\title{
Ammonia converter Simulation and Optimization Based on an Innovative Correlation for $\left(K_{\mathrm{P}}\right)$ Prediction
}

\author{
Muhammad El-Gharbawy ${ }^{1}$, Walaa Shehata ${ }^{2}$, Fatima Gad ${ }^{2}$ \\ ${ }^{1}$ Miser Fertilizers Production Company, Technical Studies, Development and Energy Optimization Department \\ ${ }^{2}$ Suez University, Faculty of Petroleum and Mining Engineering, Department of Petroleum Refining and Petrochemical Engineering
}

\begin{abstract}
In this paper, the simulation and optimization of an industrial ammonia synthesis reactor is illustrated. The converter under study is of a vertical design, equipped with three radial-flow catalyst beds with inter-stage cooling and two quenching points. For building the model, a modified kinetic equation of ammonia synthesis reaction, based on TemkinPyzhev equation and an innovative correlation for $\left(\mathrm{K}_{\mathrm{P}}\right)$ prediction, was developed in suitable form for the implementation in Aspen HYSYS plug flow reactor using the spreadsheet embedded in the software with the introduction of some invented simulation techniques. A new parameter, which is a function of (T, P and $\alpha)$, was introduced into the reaction rate equation to account for the variation of $K_{P}$ with pressure. The simulation model is able to describe the converter behavior with acceptable accuracy. A case study was done, using Aspen HYSYS Optimizer, illustrated the optimum reactor temperature profile, after 12 years of operation, to achieve maximum production. The result predicts an increase of 8 tons ammonia per day accompanied with an increase of steam production of 12 tons per day.
\end{abstract}

Keywords: Ammonia synthesis; Reactor modeling; Aspen HYSYS; Optimization; Temkin-Pyzhev; Equilibrium

\section{Introduction}

Ammonia is widely known as an important chemical for industry, it is involved in manufacturing of many products like; plastics, fibers and fertilizers for it is the principle source of all nitrogen fertilizers since 1945. Its production rate in industry, compared to all other inorganic chemicals, is almost the highest ${ }^{(1)}$.

Ammonia synthesis reaction proceeds, in principle, by Haber-Bosch process from its elemental components: hydrogen and nitrogen, without side products, i.e. it is a clean process, with stable ammonia product $^{(2)}$.

This exothermic reaction proceeds at constant pressure with reduction in volume (moles), refer to Equation $(1.1)^{(3)}$. Accordingly; decreasing reaction temperatures increases the equilibrium constant $\mathrm{K}_{\mathrm{P}}$, while increasing reaction pressure increases the equilibrium concentration of ammonia in the mixture; based on the theory of ideal gases ${ }^{(4)}$. 


$$
0.5 \mathrm{~N}_{2}+1.5 \mathrm{H}_{2} \leftrightarrow \mathrm{NH}_{3} \quad \Delta \mathrm{H}_{298}=-46.22 \mathrm{~kJ} / \mathrm{mole}
$$

In reality, the equilibrium constant $K_{P}$ of Haber-Bosch reaction does not follow the theory of ideal gases, which states that the pressure of reaction has no effect on $K_{P}$, but it was found that $K_{P}$ exhibits change by changing the reaction pressure ${ }^{(5)}$. This leads many researchers to study this effect and develop correlations to calculate $K_{P}$ for various temperatures and pressures. In this study, a new approach, proposed by El-Gharbawy et al $^{(6)}$, is used for $K_{P}$ prediction. The new correlation is proven to be accurate enough in the industrial range of the process ${ }^{(6)}$.

One of the most applicable equations describing the kinetics of ammonia formation reaction is that developed by Temkin and Pyzhev ${ }^{(4)}$. Their equation based on the assumption that hydrogen and ammonia have no effect on the rate of nitrogen adsorption on the non-uniform catalyst surface, i.e. the rate-determining step is nitrogen dissociative adsorption $^{(2)}$. Refer to Equation (1.2) ${ }^{(7)}$.

$$
\mathrm{R}_{\mathrm{NH} 3}=\mathrm{K}_{1}\left(\mathrm{P}_{\mathrm{N} 2}\left(\mathrm{P}_{\mathrm{H} 2}{ }^{1.5} / \mathrm{P}_{\mathrm{NH} 3}\right)^{\alpha}-\mathrm{K}_{2}\left(\mathrm{P}_{\mathrm{NH} 3} / \mathrm{P}_{\mathrm{H} 2}{ }^{1.5}\right)^{1-\alpha}\right)
$$

Where $\mathrm{R}_{\mathrm{NH} 3}$ is the intrinsic rate of ammonia formation reaction, the constant $\alpha$ has a value between (0-1); $\mathrm{K}_{1}$ and $\mathrm{K}_{2}$ are reaction velocity constant for the forward and reverse reactions, respectively, and are defined according to Arrhenius expression ${ }^{(4)}$.

Where; $\mathrm{A}$ is the frequency factor, $\mathrm{E}$ is the activation energy of reaction, $\mathrm{R}$ is gas constant and $\mathrm{T}$ is absolute temperature.

\section{Methodology}

Aspen HYSYS simulator version 12.0 is used, based on GCEOS thermodynamic package, which is the best thermodynamic package provided by the software for reaction enthalpy calculation, according to our trials of the plant field data.

Imbedded spreadsheet, which is a feature provided by Aspen HYSYS software, is used to implement the innovative $K_{P}$ correlation within a modified form of Temkin-Pyzhev equation.

Aspen HYSYS provides templets of each equipment or unit operation, which are used to build the model, being adjusted by implementing our equations using the imbedded spreadsheet feature.

\subsection{Ammonia Converter}

The ammonia converter under study is a cylindrical vessel, about $20 \mathrm{~m}$ high, with an internal diameter of $2.8 \mathrm{~m}$. The vessel is combined with three catalyst beds of synthesis catalyst with the following volumes: $17.9,13.6$ and $20.8 \mathrm{~m}^{3}$ for $1^{\text {st }}, 2^{\text {nd }}$ and $3^{\text {rd }}$ beds 
respectively. For a schematic drawing of a typical ammonia converter of this type refer to Figure (2.1) in Section

The catalyst beds are of radial- flow type, i.e. each bed is of hollow cylindrical tube. The feed, for each bed, enters radially from outside to inside into the core tube. The first bed loaded with pre-reduced catalyst in the form of grey granules with a size range of $1.5-3$ $\mathrm{mm}$ and a bulk density of approximately $2.3 \mathrm{~kg} / \mathrm{L}$ after vibration. The second and third beds are loaded with unreduced catalyst in the form of black granules with a size range of $1.5-3 \mathrm{~mm}$ and a bulk density of approximately $2.9 \mathrm{~kg} / \mathrm{l}$ after vibration.

This design achieves a favorable temperature flow over the entire height of the catalyst through inter-stage cooling of the reaction gas. Cooling between catalyst beds is achieved by indirect two core heat exchange, through exchangers E01 and E02, against the gas entering the reactor. Inlet Temperatures of the $1^{\text {st }}$ and $2^{\text {nd }}$ catalyst beds are controlled by bypassing quantities of circulating gas through HV0, HV01 and HV02 to be injected, directly in to the reactor as quench streams, and mixed with the hotter stream upstream of $1^{\text {st }}$ and $2^{\text {nd }}$ beds. Refer to Figure (2.2)

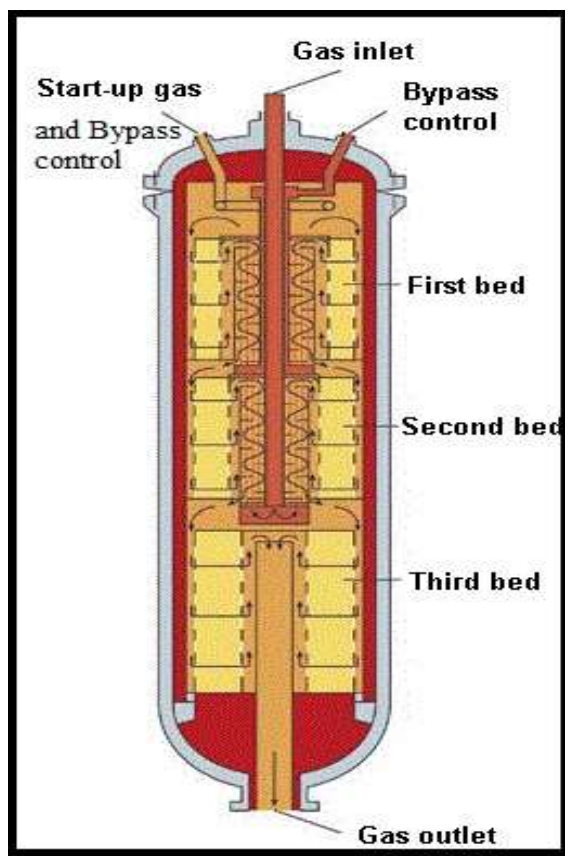

Figure (2.1): Schematic configuration of the simulated ammonia converter

\subsection{Model assumptions:}

The model is built with the following assumptions:

- Steady state condition of the converter under investigation.

- Each of the three reactor beds are simulated using plug flow reactor unit operation in HYSYS simulator, and reaction equations of each reactor bed is 
implemented and adjusted by a separate spreadsheet feature provided by the simulator software. The plug flow reactor unit operation is one dimensional pseudo-homogeneous model following the conceptual plug flow reactor model assumptions, i.e. no temperature, concentration and pressure gradient in the radial direction of the reactor cylindrical bed.

- Each of the three catalyst beds are approximated from hollow cylindrical radial flow bed into a cylindrical axial flow bed as illustrated in Table (2.1), refer also to Figure (2.1). It should be noted that the depth of catalyst bed which represents the path taken by the gas stream through the bed is expressed by length, while the cylindrical area faced by the gas stream is approximated to a circle.

- Bed void fraction, for the assumed axial-flow cylindrical beds, are estimated based on the available field data, to give the same overall pressure drop $D_{P}$ of the original convertor for the whole operating range of flow and pressure.

- For $\mathrm{D}_{\mathrm{P}}$ calculation, the three valves HVO, HV01 and HV02, and both heat exchangers shell and tube sides take the same fixed $D_{P}$ value of 0.2 bar, while each of the reactor beds uses Ergun equation provided by the simulation software to calculate $\mathrm{D}_{\mathrm{P}}$ based on the assigned void fraction for each and other required parameters, which allows dynamic $D_{\mathrm{P}}$ calculation of the reactor beds for various loads.

- The Recycle unit operation function, provided by HYSYS simulator software, is used in our calculations as a mathematical tool to perform try and error trails for the implemented equations in the embedded spreadsheet; this is a new approach $\equiv$ an innovative technique.

To fulfill this purpose, Initial estimates for recycle streams composition, temperature and pressure are given to allow the recycle function to start try and error estimation.

- The inter-stage heat exchangers of the reactor are simulated as simple weighted model. This choice facilitates the model calculations; where there is no need to simulate these heat-exchangers as a rated or full rated model.

\begin{tabular}{|c|c|c|c|c|}
\hline \multicolumn{5}{|c|}{ Table (2.1): equivalent bed size used in simulation } \\
\hline \multirow{2}{*}{ Reactor Bed } & \multirow{2}{*}{ Volume $\left(\mathrm{m}^{3}\right)$} & Approximated Size $(\mathrm{m})$ & \multirow{2}{*}{ Void Fraction } \\
\cline { 3 - 4 } & & Diameter & Length & \\
\hline $1^{\text {st }}$ & 17.46 & 0.6020 & 6.077 & 0.24 \\
\hline $2^{\text {nd }}$ & 13.43 & 0.6940 & 4.964 & 0.241 \\
\hline $3^{\text {rd }}$ & 20.96 & 0.9160 & 5.398 & 0.225 \\
\hline
\end{tabular}

\subsection{Equations and correlations}

The equation of Temkin-Pyzhev according to (Dyson and Simon 1968) ${ }^{(2)}$, is used, which has the following expression: 


$$
\mathrm{R}_{\mathrm{NH} 3}=\mathrm{f} \mathrm{K}_{2}\left(\mathrm{~K}_{\mathrm{P}}{ }^{2} \mathrm{P}_{\mathrm{N} 2}\left(\mathrm{P}_{\mathrm{H} 2}{ }^{3} / \mathrm{P}_{\mathrm{NH} 3}{ }^{2}\right)^{\alpha}-\left(\mathrm{P}_{\mathrm{NH} 3}{ }^{2} / \mathrm{P}_{\mathrm{H} 2}{ }^{3}\right)^{1-\alpha}\right)
$$

$\mathrm{K}_{\mathrm{P}}$ is the equilibrium constant for synthesis reaction, and is calculated according to ElGharbawy et al correlation ${ }^{(6)}$; refer to Equations (2.2) to (2.11).

$\mathrm{K}_{\mathrm{P}}^{2}=5.9501 * 10^{-13} \mathrm{e}^{\sigma / \mathrm{RT}}\left(\mathrm{K}_{\mathrm{X}}{ }^{0.75}-\mathrm{K}_{\mathrm{Y}}{ }^{0.75-\theta}\right)$

Where;

$\log \left(\mathrm{K}_{\mathrm{X}}\right)=\mathrm{P}_{\mathrm{X}}(\mathrm{A}+\mathrm{B}+\mathrm{C}+\mathrm{D})$

$\mathrm{P}_{\mathrm{X}}=\mathrm{P}^{\mathrm{X}}$

$\mathrm{X}=1+(2 / \mathrm{P})^{\mathrm{a}}-\left(2.5 * 10^{-13} \mathrm{P}^{\mathrm{b}}\right)$

$\mathrm{A}=1.1515^{*} 10^{-7} \mathrm{P}_{\mathrm{X}}^{\mathrm{c}} /(\mathrm{T}-\mathrm{d})$

$\mathrm{B}=\mathrm{P}_{\mathrm{X}}{ }^{\mathrm{f}} 1.049 \wedge\left(1.21(\mathrm{~T}-\mathrm{g}) \mathrm{P}_{\mathrm{X}}{ }^{\mathrm{h}}(\mathrm{T}+5200)^{\mathrm{i}}\right)$

$\mathrm{C}=1+(\mathrm{T}-\mathrm{j})^{\mathrm{k}} /\left(\mathrm{P}_{\mathrm{X}}{ }^{1}+4950\right)$

$\mathrm{D}=1 /\left(\mathrm{T}^{\mathrm{m}}-2 / \mathrm{T}^{4}\right)-\mathrm{T}^{\mathrm{n}}-\left(0.30026 * \mathrm{~T}^{\mathrm{q}}\right)$

$\mathrm{K}_{\mathrm{Y}}=1 /\left(\mathrm{P}_{\mathrm{X}}{ }^{\mathrm{r}}+\mathrm{T}+\mathrm{s}\right)$

$\Theta=8600 \mathrm{P}_{\mathrm{X}}^{\mathrm{u}}$

$\mathrm{P}$ in atm, $\mathrm{T}$ in ${ }^{\circ} \mathrm{K}, \mathrm{R}$ is the universal gas constant $=8.3144598$ Joule / Mole ${ }^{\circ} \mathrm{K}$ and $(\sigma, \mathrm{a}$, b, c... u) are constants; refer to Table (2.2).

\begin{tabular}{|c|c|c|c|}
\hline \multicolumn{4}{|c|}{ Table (2.2): values of constants involved in the new correlation for $\mathbf{K}_{\mathbf{P}}$ estimation } \\
\hline Constant & Value & Constant & Value \\
\hline$\sigma$ & 109000 & $\mathrm{j}$ & 600 \\
\hline $\mathrm{a}$ & 1.34 & $\mathrm{k}$ & 0.553 \\
\hline $\mathrm{b}$ & 4.5 & $\mathrm{l}$ & 2.3255 \\
\hline $\mathrm{c}$ & 2.595 & $\mathrm{~m}$ & 0.1 \\
\hline $\mathrm{d}$ & 508 & $\mathrm{n}$ & -0.2270499 \\
\hline $\mathrm{f}$ & 0.92 & $\mathrm{q}$ & -0.0037 \\
\hline $\mathrm{g}$ & 75 & $\mathrm{r}$ & 0.99 \\
\hline $\mathrm{h}$ & -0.68 & $\mathrm{~s}$ & 5 \\
\hline $\mathrm{i}$ & -1.673 & $\mathrm{u}$ & -2.5079 \\
\hline
\end{tabular}

$\mathrm{K}_{1}$ and $\mathrm{K}_{2}$, are related to $\mathrm{K}_{\mathrm{P}}$, thus:

$\mathrm{K}_{\mathrm{P}}{ }^{2}=\mathrm{K}_{1} / \mathrm{K}_{2}$ 
$\mathrm{K}_{\mathrm{P}}$ can be written in another form to incorporate the parameters account for pressure effect, previously introduced by our correlation; as following:

$\mathrm{K}_{\mathrm{P}}^{2}=\mathrm{K}_{1}^{*}\left(\mathrm{~K}_{\mathrm{X}}{ }^{0.75}-\mathrm{K}_{\mathrm{Y}}{ }^{0.75-\theta}\right) / \mathrm{K}_{2}$

Where $\left(\mathrm{K}_{\mathrm{X}}{ }^{0.75}-\mathrm{K}_{\mathrm{Y}}{ }^{0.75-\theta}\right)$ are the parameters account for pressure effect on $\mathrm{K}_{\mathrm{P}}$, which are assigned the symbol $\mathrm{K}_{\mathrm{w}}$. so that;

$\mathrm{K}_{\mathrm{w}}=\left(\mathrm{K}_{\mathrm{X}}{ }^{0.75}-\mathrm{K}_{\mathrm{Y}}{ }^{0.75-\theta}\right)$

$\mathrm{K}_{1}=\mathrm{K}_{1}{ }_{1} \mathrm{~K}_{\mathrm{w}}$

$\mathrm{K}_{1}$ and $\mathrm{K}_{2}$ are reaction velocities for the forward and reverse reactions, respectively. $\mathrm{K}_{1}{ }_{1}$ and $\mathrm{K}_{2}$ can be defined, in principle, according to Arrhenius expression:

$$
\mathrm{K}=\mathrm{A} \mathrm{e} \mathrm{e}^{-\mathrm{E} / \mathrm{RT}}
$$

Where; $\mathrm{A}$ is the frequency factor, $\mathrm{E}$ is the activation energy of reaction, $\mathrm{R}$ is the gas constant and $\mathrm{T}$ is absolute temperature $\left(\mathrm{K}^{\circ}\right)$, with the following values:

\begin{tabular}{|l|}
\hline $\mathrm{A}_{1}=595.11$ \\
\hline $\mathrm{A}_{2}=1.000119 * 10^{12}$ \\
\hline $\mathrm{E}_{1}=49800 \mathrm{KJ} / \mathrm{Kgmole}$ \\
\hline $\mathrm{E}_{2}=158800 \mathrm{KJ} /$ Kgmole \\
\hline $\mathrm{R}=8.3144598 \mathrm{~J} /$ Mole. $^{\circ}$ \\
\hline
\end{tabular}

Kinetic Equation (2.17), which is the form being used in our simulation, takes its final form, by substituting Equations (2.12), (2.13), (2.14) and (2.15) into Equation (2.1):

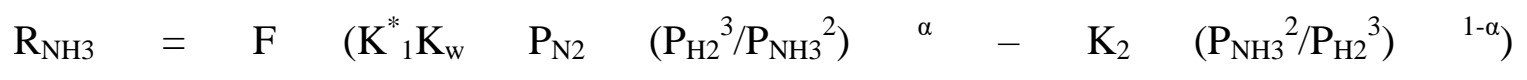

The constant $\alpha$ in both Equations (2.1) and (2.7) has assigned a value of (0.5) as being chosen by Temkin ${ }^{(4)}$.

$\mathbf{F}$ is the catalyst activity factor, and its formula is according to Equation (2.18), where $\mathbf{A}$ is catalyst activity; $\mathbf{0}<\mathbf{A}<\mathbf{1}$.

$\mathrm{F}=$

$\mathbf{X}$ is an empirical correlation, developed by us to account for activity change with temperature, which is based on our converter start of run and end of run data, according to the following:

$$
\mathrm{X}=\mid\left(\mathrm{T}_{\mathrm{EOR}}-\mathrm{T}_{\text {bin }}\right) / \text { Scale } \mid
$$


Where $\mathrm{T}_{\mathrm{EOR}}$ is the inlet operating temperature of the bed at the end of run situation, and $\mathrm{T}_{\text {bin }}$ is the actual inlet operating temperature of the bed, and scale is the difference between end of run and start of run temperatures for each bed, all in $\mathrm{C}^{\circ}$, and their values are expressed as following:

\begin{tabular}{|l|}
\hline For the $1^{\text {st }}$ catalyst bed: \\
\hline $\mathrm{T}_{\mathrm{EOR}}=400 \mathrm{C}^{\circ}$ \\
\hline Scale $=15 \mathrm{C}^{\circ}$ \\
\hline For the $2^{\text {nd }}$ catalyst bed: \\
\hline $\mathrm{T}_{\mathrm{EOR}}=438 \mathrm{C}^{\circ}$ \\
\hline Scale $=6 \mathrm{C}^{\circ}$ \\
\hline For the $3^{\text {rd }}$ catalyst bed: \\
\hline $\mathrm{T}_{\mathrm{EOR}}=424 \mathrm{C}^{\circ}$ \\
\hline Scale $=4 \mathrm{C}^{\circ}$ \\
\hline
\end{tabular}

Ammonia production flow rate is calculated according to Equation (2.20), where 170 represents the ammonia leaving the system with the off gas stream.

Ammonia production $=\left(\right.$ Ammonia $_{\text {out }}-$ Ammonia $\left._{\text {in }}-170\right)$

\subsection{Model Simulation and Analysis}

The model is built taking Test Run actual plant conditions as a reference, which is the documented state monitored, followed and tested by technology vendor. This gave us the advance of verifying our model by comparing its results with that of the vendor model and with the recorded field data as well.

Some analyses were done on the model after verification as an illustration of its reliability.

Refer to Figure (2.2) which is a simplified sketch of the ammonia converter represent the configuration prepared for simulation environment.

\subsubsection{Model basis}

At the test of run situation the following data, as illustrated in Table (2.3), are applicable considering the three valves HV0, HV01 and HV02 are open 100\%, and each of the three reactor beds is assigned a catalyst activity value $\mathbf{A}$ of $92 \%$, which is the estimated value documented by the catalyst vendor for this age. Reactor profile is expressed by the field data as following, refer to Table (2.4).

Each of the three reactor beds has assigned a separate spreadsheet which is used to calculate $\mathrm{K}_{\mathrm{w}}$ and other calculated parameters that are not provided in the software templets. 


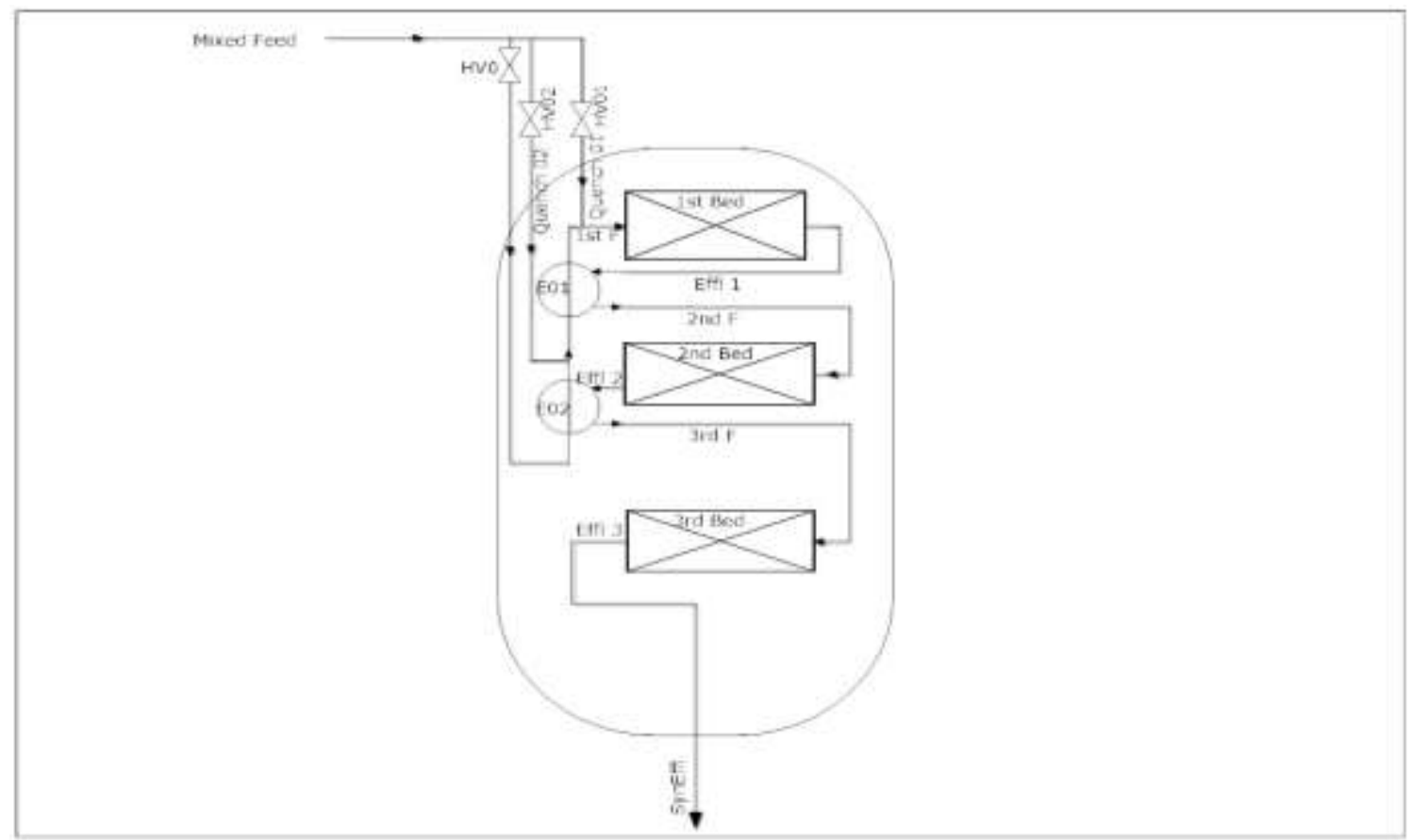

Figure (2.2): Sketch of ammonia converter prepared for simulation

In HYSYS software, by using (send to) feature from any field in the reaction templet, or any other templet, the field is sent to the assigned cell in the spreadsheet where any further calculation can be done, and the result is simultaneously assigned back to the templet field.

\begin{tabular}{|c|c|c|c|}
\hline \multicolumn{4}{|c|}{ Table (2.3): Feed condition at test of run situation } \\
\hline Data & & tream Mol. & \\
\hline Components & Mixed Feed & Quench 01 & Quench 02 \\
\hline $\mathbf{N}_{2}$ & \multicolumn{3}{|c|}{0.1986} \\
\hline $\mathbf{H}_{2}$ & \multicolumn{3}{|c|}{0.6230} \\
\hline Ar & \multicolumn{3}{|c|}{0.0589} \\
\hline $\mathbf{N H}_{3}$ & \multicolumn{3}{|c|}{0.0270} \\
\hline $\mathbf{C}_{1}$ & \multicolumn{3}{|c|}{0.0943} \\
\hline Molar flow (Kgmole/h) & 26409.44 & 3155 & 3155 \\
\hline Operating $\mathbf{T}\left({ }^{\circ} \mathbf{C}\right)$ & $*$ & * & * \\
\hline Operating P (Bar. a) & 170.9 & 170.7 & 170.7 \\
\hline
\end{tabular}

* Mixed feed stream temperature is manipulated to simulate the required $3 \mathrm{r}$ bed inlet temperature, as the exact field temperature of this stream is not accurate enough; here it takes the value of $257 \mathrm{C}^{\circ}$ while the recorded, inaccurate, field temperature is $265 \mathrm{C}^{\circ}$.

In steady state simulation mode, the outlet temperature and pressure of the reactor stream are the temperature and pressure used by the kinetic equation to solve for the composition 
using the thermal equation solution as constrains, the software calculation core uses try ant error method to achieve that, by giving initial temperature and pressure trial and solve with calculated error to give another trial until final solution for outlet temperature and pressure are estimated to fit for the kinetic equation and thermal equations. In order to use our implemented equations, we used the same philosophy using Recycle function provided by the software. It is used to achieve try and error function, refer to Section (2.2).

\begin{tabular}{|c|c|c|}
\hline \multicolumn{2}{|c|}{ Table (2.4): Reactor profile at test of run situation } \\
\hline Data & $\mathbf{T}_{\text {in }}\left({ }^{\circ} \mathrm{C}\right)$ & $\mathbf{T}_{\text {out }}\left({ }^{\circ} \mathbf{C}\right)$ \\
\hline $\mathbf{1}^{\text {st }}$ Bed & $381,371.391^{* * *}$ & $519,519,512^{* * *}$ \\
\hline $\mathbf{2}^{\text {nd }}$ Bed & $430,434,437^{* * *}$ & $471,475,479^{* * *}$ \\
\hline $\mathbf{3}^{\text {rd }}$ Bed & $411,411,416^{* * *}$ & $439,443,448^{* * *}$ \\
\hline \multicolumn{2}{|c|}{15.84} \\
\hline Ammonia Conc.out $\%$ & 1220 \\
\hline Daily production (Ton) & $50.83^{* * * *}$ \\
\hline Mean production rate (Ton/hr) & \multicolumn{2}{|c|}{1.7} \\
\hline D $_{\mathbf{P}}$ across the reactor Sys. (bar) & \multicolumn{2}{|c|}{} \\
\hline
\end{tabular}

***Each bed has 3 field temperature indicators for both inlet and outlet, we chose a value, for each bed inlet and outlet within the range given by each three values, in order to solve the model with matched values for other certain parameters, e.g. outlet composition.

$* * * *$ this value is calculated as the mean value in $24 \mathrm{hrs}$, and it is the value used in the simulation, however it's an approximation.

\subsection{Simulation results}

The model case is solved, refer to Figure (2.3) which illustrates the simulated configuration of the converter.

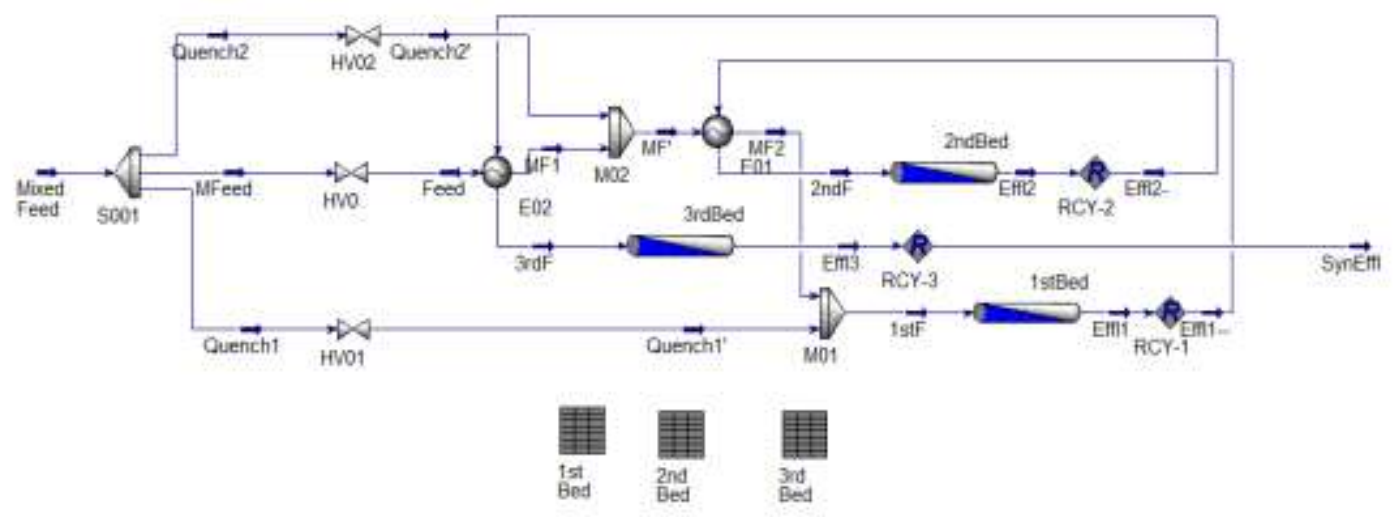

Figure (2.3): The configuration of the model built by HYSYS 12.0 
Results are compared with the real field data and the simulation results by technology vendor model, refer to Table (2.5). According to the table, results show excellent agreement with field data compared to vendor simulated data, especially the reactor temperature profile and ammonia exist concentration.

\begin{tabular}{|c|c|c|c|}
\hline \multicolumn{3}{|c|}{ Table (2.5): comparison between our results, actual and vendor simulation results } \\
\hline Data & Field Data & Vendor Simulated Data & Simulation Data \\
\hline $\begin{array}{c}\text { Circulation rate } \\
\left(\mathbf{N m}^{\mathbf{3}} / \mathbf{h r}\right)\end{array}$ & $546500 * * * * *$ & 568472 & 591930 \\
\hline Converter inlet T $\left(\mathbf{C}^{\circ}\right)$ & 265 & 254.9 & 257 \\
\hline Inlet P (bar.a) & 170.9 & 170.9 & 170.9 \\
\hline $\mathbf{1}^{\text {st }}$ Bed Tin $\left(\mathbf{C}^{\circ}\right)$ & $381,371.391$ & 396.3 & 393.5 \\
\hline $\mathbf{1}^{\text {st }}$ Bed Tout $\left(\mathbf{C}^{\circ}\right)$ & $519,519,512$ & 513.2 & 509.3 \\
\hline $\mathbf{2}^{\text {nd }}$ Bed Tin $\left(\mathbf{C}^{\circ}\right)$ & $430,434,437$ & 433.5 & 437 \\
\hline $\mathbf{2}^{\text {nd }}$ Bed Tout $\left(\mathbf{C}^{\circ}\right)$ & $471,475,479$ & 474.2 & 477.2 \\
\hline $\mathbf{3}^{\text {rd }}$ Bed Tin $\left(\mathbf{C}^{\circ}\right)$ & $411,411,416$ & 413.5 & 415 \\
\hline $\mathbf{3}^{\text {rd }}$ Bed Tout $\left(\mathbf{C}^{\circ}\right)$ & $439,443,448$ & 450.3 & 15.84 \\
\hline $\mathbf{N H}_{\mathbf{3}}$ Conc.out $\%$ & 15.84 & 16.39 & 50.85 \\
\hline $\begin{array}{c}\text { Ammonia Production } \\
\text { rate }(\text { Ton/hr) }\end{array}$ & 50.83 & 50.79 & \\
\hline
\end{tabular}

$* * * * *$ Inlet flowmeter value is proven to be not accurate, so the only data that can be relied on is the inlet and exit ammonia concentration with the production rate to back calculate the inlet flow.

\subsection{Model Analysis}

Now we can do some analysis on the base model, we can check some properties over the whole length of the catalyst bed, i.e. the pass taken through the catalyst by the reacting gas.

Notice that the original converter is combined with radial-flow beds where the reacting gas takes the radial pass. However, the converter was modelled, as an approximation, into cylindrical bed reactor design where the flow takes the axial pass. The total length of the pass taken by syngas through the catalyst is the same in both cases, i.e. equals to $2.21 \mathrm{~m}$.

Figure (2.4) illustrates the temperature profile through the whole length of the catalyst with the inter-stage cooling. It can be seen that the first bed expresses the sharpest temperature change, though it is the shortest catalyst bed. This is due to the higher conversion takes place in this bed compared to its successors. Figure (2.5) illustrates ammonia mole fraction over the length of the catalyst as an indication of the conversion. It can be seen that the first bed achieves the highest conversion compared to the second and third beds. 


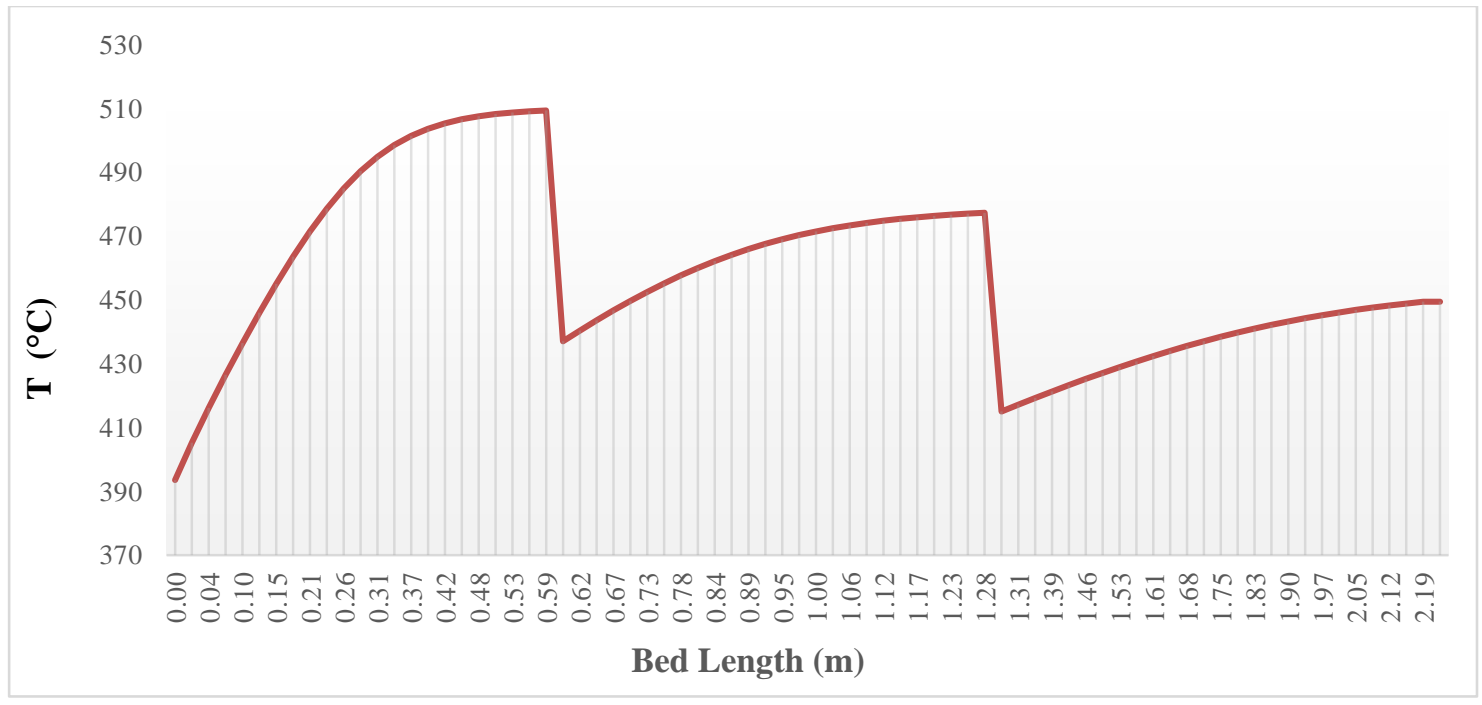

Figure (2.4): Temperature profile over the length of the catalyst.

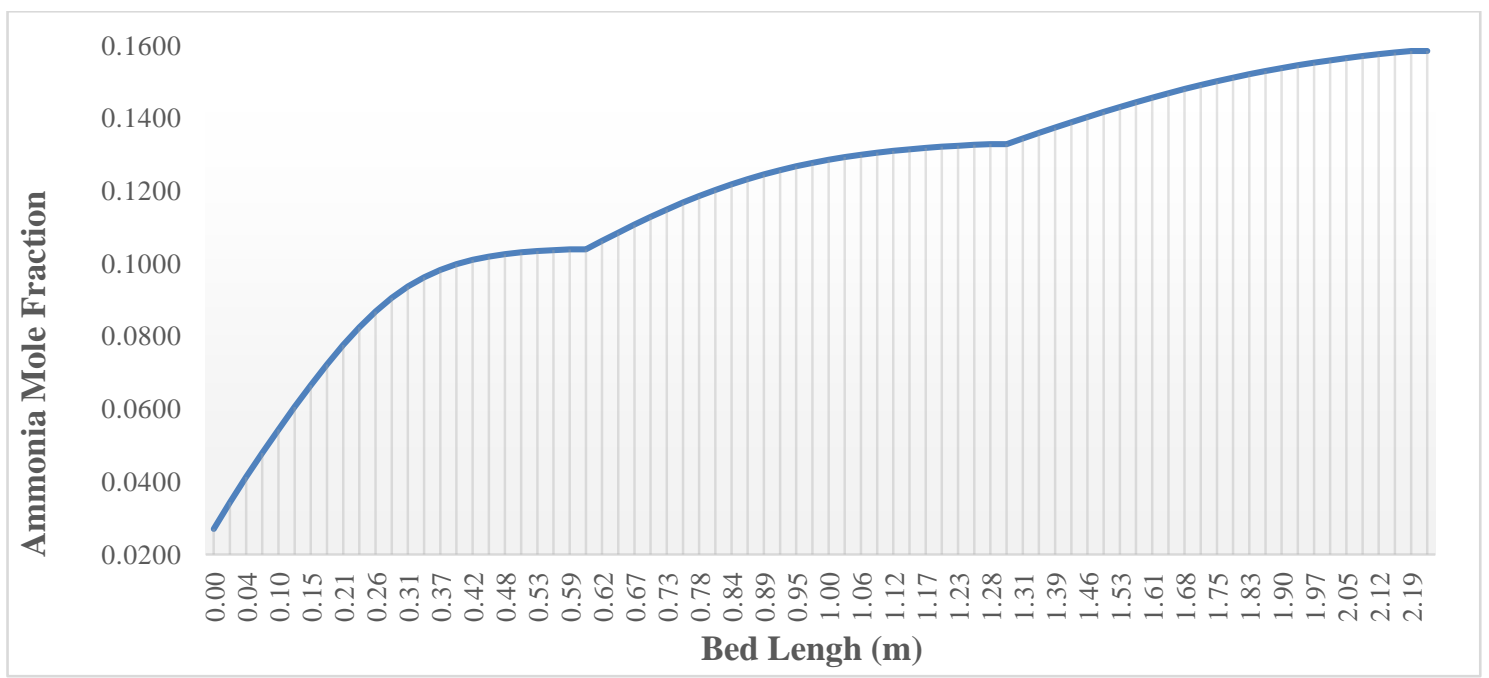

Figure (2.5): Ammonia composition over the length of the catalyst.

\subsection{Model validation}

The same calculation philosophy of the main model is applied for another case study to affirm the validation of this model, which is to calculate catalyst activity after 12 years of reactor catalyst running for various plant loads, based on the field data, and compared to vendor simulation data.

Refer to Tables (2.6) and (2.7) which illustrate field data and converter profile. The model is to simulate this situation and find which catalyst activity is adequate for the model to achieve the same conditions and reactor profile given. 


\begin{tabular}{|c|c|c|c|}
\hline \multicolumn{4}{|c|}{ Table (2.6): Feed Conditions for 12 years spent running catalyst } \\
\hline Data & Stream (Mixed Feed) & Stream (Quench 01) & Stream (Quench 02) \\
\hline Components & Mol. Frac. & Mol. Frac. & Mol. Frac. \\
\hline $\mathrm{N}_{2}$ & \multicolumn{3}{|c|}{0.2113} \\
\hline $\mathrm{H}_{2}$ & \multicolumn{3}{|c|}{0.6152} \\
\hline $\mathrm{Ar}$ & \multicolumn{3}{|c|}{0.0461} \\
\hline $\mathrm{NH}_{3}$ & \multicolumn{3}{|c|}{0.0277} \\
\hline $\mathrm{C}_{1}$ & \multicolumn{3}{|c|}{0.0997} \\
\hline $\begin{array}{l}\text { Molar flow } \\
\text { (Kgmole/h) }\end{array}$ & 26327.2 & 3161 & 3161 \\
\hline Op. Temp. $\left(\mathrm{C}^{\circ}\right)$ & * & * & * \\
\hline Op. Press. (Bar. a) & 171.9 & 171.5 & 171.5 \\
\hline
\end{tabular}

*Mixed feed stream temperature is manipulated to achieve the required $3 \mathrm{r}$ bed inlet temperature, as the exact field temperature of this stream is not accurate enough; here it takes the value of $263.5 \mathrm{C}^{\circ}$ while the recorded field temperature is $269 \mathrm{C}^{\circ}$.

\begin{tabular}{|c|c|c|}
\hline \multicolumn{2}{|c|}{ Table (2.7): Reactor profile for 12 years spent running catalyst } \\
\hline Data & $\mathbf{T}_{\text {in }}\left(\mathbf{C}^{\circ}\right)$ & $\mathbf{T}_{\text {out }}\left(\mathbf{C}^{\circ}\right)$ \\
\hline $\mathbf{1}^{\text {st }}$ Bed & $375,385.390^{* * *}$ & $512,514,510^{* * *}$ \\
\hline $\mathbf{2}^{\text {nd }}$ Bed & $432,434,438^{* * *}$ & $472,475,479^{*} * *$ \\
\hline $\mathbf{3}^{\text {rd }}$ Bed & $415,418,422^{* * *}$ & $445,449,453^{* * *}$ \\
\hline \multicolumn{2}{|c|}{15.75} \\
\hline Ammonia Conc. ${ }_{\text {out }} \%$ & 1202 \\
\hline Daily production (Ton) & $50.08 * * *$ \\
\hline Mean production rate (Ton/hr) & \multicolumn{2}{|c|}{1.8} \\
\hline D $_{\mathbf{P}}$ across the reactor Sys. (bar) & \multicolumn{2}{|c|}{} \\
\hline
\end{tabular}

***Each bed has 3 temperature indicators for inlet and outlet stream, we choose a value for each three values, for each bed inlet and outlet as well, which matches with the full converter data in the simulation.

$* * * *$ this value is calculated as the mean value in $24 \mathrm{hrs}$, and it is the value used in the simulation, however it's an approximation.

Results are illustrated in Table (2.8) in comparison with technology vendor simulation results, with calculated activity for reactor three beds of $\underline{65 \%, 61 \% \text { and } 61 \%}$ with a mean activity of $\underline{\mathbf{6 2 . 3 \%}}$.

Technology vendor estimated the mean catalyst activity of the reactor to be $\underline{\mathbf{6 3 \%}}$. Results of this case study affirm the validation of the model and its core equations as well. 


\begin{tabular}{|c|c|c|c|}
\hline \multicolumn{4}{|c|}{$\begin{array}{c}\text { Table (2.8): comparison between our results, actual and vendor simulation results for } 12 \\
\text { years spent running catalyst }\end{array}$} \\
\hline Data & Field Data & Vendor Simulated Data & Simulation Data \\
\hline $\begin{array}{l}\text { Circulation rate } \\
\left(\mathrm{Nm}^{3} / \mathrm{hr}\right)\end{array}$ & 561550 & 573203 & 590087 \\
\hline Converter inlet $\mathbf{T}\left(\mathbf{C}^{\circ}\right)$ & 269 & 264.1 & 263.5 \\
\hline Inlet P (bar.a) & 171.7 & 171.7 & 171.7 \\
\hline $1^{\text {st }} \operatorname{Bed} \operatorname{Tin}\left(\mathrm{C}^{\circ}\right)$ & $375,385,390$ & 384.9 & 396 \\
\hline $1^{\text {st }}$ Bed Tout $\left(C^{\circ}\right)$ & $512,514,510$ & 508.3 & 510.8 \\
\hline $2^{\text {nd }}$ Bed Tin $\left(C^{\circ}\right)$ & $432,434,438$ & 438.2 & 436 \\
\hline $2^{\text {nd }}$ Bed Tout $\left(C^{\circ}\right)$ & $472,475,479$ & 473.6 & 476.8 \\
\hline $3^{\text {rd }}$ Bed Tin $\left(C^{\circ}\right)$ & $415,418,425$ & 423.7 & 421.2 \\
\hline $3^{\text {rd }}$ Bed Tout $\left(C^{\circ}\right)$ & $445,449,453$ & 453.4 & 451.9 \\
\hline $\mathrm{NH}_{3}$ Conc.out $\%$ & 15.75 & 16.12 & 15.76 \\
\hline $\begin{array}{c}\text { Ammonia Production } \\
\text { per day (Ton) }\end{array}$ & 1202 & 1201.8 & 1203 \\
\hline
\end{tabular}

\section{Reactor profile optimization Results}

Reactor profile at the current situation; 12 years running with catalyst activities for $1^{\text {st }}, 2^{\text {nd }}$ and $3^{\text {rd }}$ bed of $65 \%, 61 \%$ and $61 \%$, respectively, is to be optimized for higher reactor production, using the same feed condition in Table (2.6).

The variable optimized are the inlet temperatures of each catalyst bed, the change of reactor temperature profile can be achieved in practice by controlling valves HV0, HV01 and HV02. The change of these temperatures cost nothing, while any increase in ammonia production as a result is a clean gain, in both production and heat generated.

The optimizer configuration applied on the model is (Hyprotech SQP Optimizer) which is defined by Aspen HYSYS as: Sequential Quadric Programming optimizer solver; this solver features step size restriction, decision variable and objective function scaling, and problem-independent and scale-independent relative convergence test. The algorithm also ensures that the model is evaluated only at points feasible with respect to the variable bounds. The quadric programing (QP) routine used is based on the active set algorithm described in the following paper; P. E. Gill and W. Murray, "Numerically Stable Methods for Quadratic Programming", Mathematical Programming, Vol. 14, No. 1, 1978, pp. 349-372.

Both inlet temperatures of the $1^{\text {st }}$ and $2^{\text {nd }}$ beds are assigned as optimization variable. The objective function is chosen to be ammonia final mole fraction which is the only parameter that may indicate and increase the productivity at constant inlet flow. 
Optimizer works for maximizing the objective function, i.e. ammonia production, by manipulating the optimization variables, i.e. inlet temperatures of the $1^{\text {st }}$ and $2^{\text {nd }}$ beds, until it solves for the maximum possible production.

Table (2.9) illustrates the results of optimizer compared to the field data and nonoptimized simulation result which was already illustrated in Table (2.8).

\begin{tabular}{|c|c|c|c|}
\hline \multicolumn{3}{|c|}{$\begin{array}{c}\text { Table (2.9): comparison between optimization results, actual and simulation results } \\
\text { for 12 years spent running catalyst }\end{array}$} \\
\hline Data & Field Data & Simulation Results & $\begin{array}{c}\text { Optimization } \\
\text { Results }\end{array}$ \\
\hline $\begin{array}{c}\text { Circulation rate } \\
\left(\mathbf{N m}^{3} / \mathbf{h r}\right)\end{array}$ & 561550 & 590087 & 590087 \\
\hline${\text { Converter inlet T }\left(\mathbf{C}^{\circ}\right)}^{\text {Inlet P (bar.a) }}$ & 269 & 263.5 & 263.5 \\
\hline $\mathbf{1}^{\text {st }}$ Bed Tin $\left(\mathbf{C}^{\circ}\right)$ & $375,385,390$ & 171.7 & 171.7 \\
\hline $\mathbf{1}^{\text {st }}$ Bed Tout $\left(\mathbf{C}^{\circ}\right)$ & $512,514,510$ & 396 & 391.7 \\
\hline $\mathbf{2}^{\text {nd }}$ Bed Tin $\left(\mathbf{C}^{\circ}\right)$ & $432,434,438$ & 510.8 & 507.4 \\
\hline $\mathbf{2}^{\text {nd }}$ Bed Tout $\left(\mathbf{C}^{\circ}\right)$ & $472,475,479$ & 436 & 437.3 \\
\hline $\mathbf{3}^{\text {rd }}$ Bed Tin $\left(\mathbf{C}^{\circ}\right)$ & $415,418,425$ & 476.8 & 477.9 \\
\hline $\mathbf{3}^{\text {rd }}$ Bed Tout $\left(\mathbf{C}^{\circ}\right)$ & $445,449,453$ & 421.2 & 453 \\
\hline $\mathbf{N H}_{\mathbf{3}}$ Conc.out $\%$ & 15.75 & 451.9 & 15.84 \\
\hline Ammonia Production & 1202 & 15.76 & 1210 \\
\hline per day (Ton) & & 1203 & \\
\hline
\end{tabular}

According to the illustrated results, the optimized reactor was able to increase ammonia productivity by $\mathbf{8}$ tons per day for the same feed conditions and composition of the existing reactor, accompanied with an increase of high pressure steam production of 12 tons per day, generated by recovering the excess heat released with the excess ammonia production via the downstream Waste Heat Boiler.

\section{Conclusion}

The modified form of Temkin and Pyzhev kinetic equation was able to implementation in the model built by Aspen HYSYS. The simulated model showed very accepted accuracy through: comparison with field data and the technology vendor model, analyses performed illustrating reactor profile of temperature and ammonia.

The accuracy and firmness of the model proves:

- The applicability and reliability of both the $\mathrm{K}_{\mathrm{P}}$ correlation and the modified form of kinetic equation. 
- The success of the invented techniques used in simulation, like using the Recycle unit operation of HYSYS simulator for try and error calculation in the spreadsheet.

- The successes of the approximation of the converter bed shape and configuration; from the actual radial flow into the simulated axial flow.

Concerning the simulated converter itself, the simulated model predicted that:

- The temperature profile of the converter can be optimized to increase the productivity by approximately 8 tons of ammonia per day, accompanied by an increase of steam generation via the waste heat boiler by approximately 12 tons of steam per day.

\section{References}

1. Bray, D.J., King, S.M. and Jonsson, J. A new industry benchmark for ammonia production, Haldor Topsoe A/S, Copenhagen, Denmark, 2014. Published in Nitrogen + Syngas International Conference and Exhibition.

2. Elnashaie, S.S.E.H., and Elshishini, S.S. Modelling, simulation and optimization of industrial fixed bed catalytic reactors. Topics in chemical engineering, Volume 7. US: N. p., 1993.

3. Aboul Muqeem, M. Simulation and optimization of ammonia synthesis loop. A thesis submitted to the department of chemical engineering in partial fulfillment of the requirements for the degree of Master of Science in engineering. 1988.

4. Twigg, M.V. Catalyst handbook, $2^{\text {nd }}$ ed., England: Wolfe Publishing Ltd. 1989.

5. Gillespie, L.J., Beattie, J.A. "The Thermodynamic Treatment of Chemical Equilibria in systems Composed of Real Gases. III. Mass action effects. The optimum Hydrogen: Nitrogen Ratio for Ammonia Formation in The Haber Equilibrium." Journal of the American Chemical Society, vol. 52, no. 11, Nov. 1930, pp. 4239-4246.

6. El-Gharbawy, M.M., Gad, F.K. and Shehata, W.M. "Simple new correlation for the prediction of equilibrium constant (KP) of Haber reaction covering the industrial conditions" Egyptian Journal of Petroleum, vol. 30, no. 1, 2021, pp. 1115.

7. Annabel, D. Application of Temkin kinetic equation to ammonia synthesis in large-sale reactors, Research Department, Imperial Chemical Industries Limited, Billingham Division, March 1952. 